14

\title{
Электрогенез растительно-микробного топливного элемента при параллельном и последовательном соединении ячеек
}

\author{
(C) Т.Э. Кулешова, ${ }^{1}$ Н.Р. Галль, ${ }^{1}$ А.С. Галушко, ${ }^{2}$ Г.Г. Панова ${ }^{2}$ \\ ${ }^{1}$ Физико-технический институт им. А.Ф. Иофрфе РАН, \\ 194021 Санкт-Петербург, Россия \\ ${ }^{2}$ Агрофизический научно-исследовательский институт, \\ 195220 Санкт-Петербург, Россия \\ e-mail: www.piter.ru@bk.ru
}

Поступило в Редакцию 28 мая 2020 г.

В окончательной редакции 2 октября 2020 г.

Принято к публикации 6 октября 2020 г.

\begin{abstract}
Изучены электрогенные свойства растительно-микробных топливных элементов при сборке одиночных ячеек в батарею. Экспериментально исследованы и сравнены работа одиночной ячейки и двух вариантов организации электрической цепи - параллельное и последовательное соединение ячеек. Отмечено наличие разности потенциалов $(\sim 70 \mathrm{mV})$ в варианте организации ячейки без растительного организма, которая с течением времени исчезает. Выдвинуто предположение о создании диффузионной ЭДС корневой системой с участием электрогенных хемоорганогетеротрофных микроорганизмов. Показано, что генерируемый одиночной ячейкой биоэлектрический потенциал, равный в среднем $170 \mathrm{mV}$, при последовательном соединении трех топливных элементов увеличивается лишь в 1.5 раза. При параллельном соединении трех ячеек также наблюдается повышение значений тока, отдаваемого в нагрузку, но также только в 1.5 раза и на поздних стадиях развития растений, что предположительно обусловлено запуском некоторых компенсационных механизмов, снижающих электрогенные свойства растений.
\end{abstract}

Ключевые слова: растительно-микробный топливный элемент, последовательное соединение, параллельное соединение, биоэлектрический потенциал.

DOI: 10.21883/JTF.2021.03.50531.185-20

\section{Введение}

Растительно-микробный топливный элемент (РМТЭ) - технология производства электроэнергии, основанная на взаимодействии высших растений и микроорганизмов. Считается, что органические соединения, выделяемые корнями растений, окисляются электрохимически активными бактериями, в результате чего выделяется углекислый газ и образуются свободные носители заряда (протоны и электроны) [1]. Для преобразования химической энергии в электрическую необходимо разделение зарядов, реализуемое в микробных топливных элементах следующим образом: электроны от анода переносятся на катод через внешнюю цепь; из-за наличия градиента потенциалов протоны через питательную матрицу или среду с субстратом мигрируют к катоду [2], где с участием пришедших электронов происходит восстановление молекулярного кислорода или другого катализатора и образование молекул воды [3-5].

Наиболее распространенной конфигурацией устройства РМТЭ, на которой основан принцип действия большинства двухкамерных топливных элементов [6], является конфигурация, состоящая из трех частей: анаэробной анодной камеры, ионоселективной мембраны и аэробной катодной камеры [7]. Также известна конструкции РМТЭ в виде трубчатой (tubular) модели [1], состоящей из анода в виде трубки, на дне которой расположена мембрана и под ней катод. Недостатком такой модели является относительно большое расстояние для транспортировки протона от анода через мембрану к катоду. Эта проблема решается в другой конструкции РМТЭ в виде плоской пластины (flat-plate) [8] за счет близкорасположенных анода и катода, разделенных вертикальной мембраной. Однако такая конфигурация также не получила широкого распространения из-за ограниченной эффективности, связанной со снижением производительности катода во время длительной эксплуатации. Существуют еще проточные системы на основе РМТЭ (PMFC-based flow-through systems), предназначенные для очистки сточных вод наряду с выработкой электроэнергии [9] — они представляют собой последовательно соединенные прямоугольные резервуары, наполненные органическим осадком, который служит биокатализатором. Анод располагается на дне резервуара, а катод - на поверхности водной среды, так что между электродами создается градиент потенциалов, электроны движутся к катоду, на котором атмосферный кислород служит их акцептором, в результате чего образуется вода и генерируется электричество.

Наряду с конфигурацией, важнейшими характеристиками устройства РМТЭ являются электродные материалы, которые должны иметь высокую электропроводность, биосовместимость, химическую стабильность. Наиболее часто в качестве электродов используют угле- 
родные материалы: графитовые волокно, ткань, войлок, стержень, углеродную бумагу, сетчатый стекловидный углерод, графитовые гранулы, гранулированный активированный уголь [10], обладающие высокой электропроводностью и коррозионной стойкостью, большой площадью поверхности.

Для создания растительно-микробного топливного элемента в основном используют сосудистые растения [11], водные растения - манник крупный (Glyceria maxima), рис, спартина английская (Spartina anglica), арундо тростниковый (Arundo donax) [12], травянистые растения [13], макрофиты [14], бриофиты [15] и водноболотные угодья, применяемые одновременно и для очистки сточных вод, и для производства биоэнергии [16]. Напряжение в РМТЭ, полученное на рисовых плантациях, составляет $300 \mathrm{mV}$ [17], из сточных вод пищевой промышленности - $350 \mathrm{mV}$ [18], для водно-болотных угодий Ипомеи водяной (Ipomoea aquatic) - $650 \mathrm{mV}$ [19], максимально полученное значение составило $700 \mathrm{mV}[13,20]$. Максимальный ток, полученный в [21] при использовании микроорганизмами только ризодепозитов в качестве субстрата, составил $\sim 105 \mathrm{~mA} / \mathrm{m}^{2}$. Генерация самых высоких значений тока отмечена на этапах проростков (рассады) и кущения (побегообразования) [22].

Одним из основных недостатков растительно-микробных топливных элементов является низкий КПД по отношению к падающему световому потоку. В [12] сделана теоретическая оценка КПД, понимаемого как эффективность световой конверсии, которая, в свою очередь, равна произведению теоретически максимального предела эффективности фотосинтеза, отношения корневых отложений к фотосинтезированным углеводам, доступности ризодепозитов для микроорганизмов и доли энергии, образованной микробными топливными элементами. При этом при величине освещенности в $200 \mathrm{~W} / \mathrm{m}^{2}$ выход электроэнергии составит $\sim 0.04 \mathrm{~W} / \mathrm{m}^{2}$ [12]. В эксперименте максимально достигнутое производство электроэнергии с использованием манника большого (Glyceria maxima) составило $67 \mathrm{~mW} / \mathrm{m}^{2}$ в пересчете на площадь анодной поверхности [1]; напряжение в ячейке РМТЭ возрастало с 50-го дня роста и достигало $\sim 250 \mathrm{mV}$, что соответствовало току $0.25 \mathrm{~mA}$. На основе этого рассчитанное авторами предполагаемое потенциальное производство электроэнергии составит $0.58 \mathrm{~kW} \cdot \mathrm{h} / \mathrm{m}^{2}$ в год. Авторами [4] рассчитано, что система фото-МТЭ на основе водорослей может генерировать электроэнергию на уровне $0.21 \mathrm{~kW} \cdot \mathrm{h} / \mathrm{m}^{3}$, и этот показатель может быть улучшен. Экспериментально показано, что увеличение интенсивности света может приводить к увеличению производимой мощности примерно в 6 раз [23]. Применение трубчатой модели РМТЭ при оснащении ее силиконовым газодиффузионным биокатодом, восстанавливающим кислород, и с использованием в качестве корнеобитаемой среды торфяной почвы привело к средней выработке электроэнергии, равной $21 \mathrm{~mW} / \mathrm{m}^{2}$ с площади роста тростника обыкновенного (Phragmites australis) в течение двух недель [24]. Использование феррицианидного биокатода, являющегося восстановителем кислорода, позволило увеличить выходную мощность до $679 \mathrm{~mW} / \mathrm{m}^{2}$ с зоны роста растений [24]. Наиболее оптимистическая оценка, сделанная в [7], показывает, что в естественных условиях максимальная выработка электроэнергии может составить $1.6-3.2 \mathrm{~W} / \mathrm{m}^{2}$ с площади роста растений.

Можно выделить, по крайней мере, два недостатка в описанных исследованиях. Во-первых, плотности тока и плотности мощности в основном указываются не в фактических экспериментально полученных единицах, а пересчитываются, исходя из размеров ячейки РМТЭ, нормируются либо на площадь поверхности электрода, либо на площадь зоны роста растений. Во-вторых, роль растений рассматривается лишь в качестве поставщиков ризодеопозитов [2], корневых экссудатов, таких, как муравьиная кислота, янтарная кислота и биотин идр., часть которых может выступать в качестве медиаторов электронного переноса [25], а прикорневая зона растений, по мнению авторов [2], способствует лишь созданию благоприятной среды для метаболизма бактерий. Однако известно, что сам растительный организм также является источником электрогенеза [26]. Кроме того, можно предположить, что при объединении индивидуальных РМТЭ в батарею, протекающие в системе токи и возникающие напряжения, могут повлиять на жизнедеятельность растений.

Таким образом, цель настоящей работы заключалась в экспериментальном изучении электрогенных свойств и нагрузочных способностей РМТЭ при соединении нескольких таких элементов в цепь.

\section{1. Конструкция ячеек РМТЭ}

В работах [22,27] предложен набор критериев для выбора растений, подходящих для создания РМТЭ, в их числе указаны выносливость, скорость роста, подходящее микробное сообщество в ризосфере, толерантность и способность к биоаккумуляции, доступность, адаптивность и развитость корневой системы. В дополнение к описанным свойствам актуальным является использование сельскохозяйственных культур, что позволяет одновременно получать экологически чистую энергию и продовольствие. В связи с этим в настоящей работе в качестве объекта исследования были выбраны растения салата сорта Азарт (Lactuca sativa L.). При выращивании растений в гидропонных и почвенных условиях корни растений салата выделяют во внешнюю среду разнообразные органические вещества (аминокислоты, моносахара и органические кислоты) [28,29]. Практически все эти вещества могут быть использованы электрогенными микроорганизмами. Испытания проводили на базе биополигона ФГБНУ АФИ. В качестве источника света были выбраны лампы ДНаТ с величиной фотосинтетического потока фотонов $340 \mu \mathrm{mol} /\left(\mathrm{m}^{2} \cdot \mathrm{s}\right)$, что обеспечивает 
высокую продуктивность растений и наибольшее количество поглощенной энергии фотонов: $140 \mu \mathrm{mol} /\left(\mathrm{m}^{2} \cdot \mathrm{s}\right)$ на грамм листовой поверхности в течение 10 суток, по сравнению со светильниками на основе светодиодов при одинаковом уровне облученности растений [30]. Увеличение поглощения фотонов на единицу биомассы предположительно должно повлиять на эффективность световой конверсии и последующее выделение ризодепозитов в прикорневой зоне. Продолжительность светового периода составляла $14 \mathrm{~h}$ в сутки. Температуру воздуха поддерживали в пределах $+20-22^{\circ} \mathrm{C}$ днем и $+18-20^{\circ} \mathrm{C}$ ночью, относительную влажность воздуха - 65-70\%. Для питания растений использовали раствор Кнопа.

Конструкция созданного устройства РМТЭ основана на предположении о том, что растение является источником электрогенеза как за счет поглощения и транспорта воды и минеральных веществ корневой системой, так и за счет выделения в прикорневой зоне органического вещества, используемого микроорганизмами для электрогенеза. Вследствие этого в ризосфере образуется градиент электрических потенциалов. Поэтому более простым вариантом, исключающим применение избирательно-проницаемых мембран, является использование системы электродов, контактирующей с ризосферой путем поверхностного контакта корней с проводящим материалом [31]. Видимо, разделение зарядов происходит по всей длине корневой системы, и максимальная разность потенциалов наблюдается между корневой шейкой и кончиками корней. Для того чтобы превратить эту разность в „ток в нагрузке“, электроды размещались так, чтобы один из них находился на границе воздух-питательный раствор с доступом кислорода около перехода „стебель-корень“, а другой был бы размещен в питательной корнеобитаемой среде на глубине, соответствующей длине корневой системы, что способствует развитию анаэробных условий. При выборе материала электродов важнейшими характеристиками выступала биосовместимость и пористость для обеспечения возможности прорастания корней, организации поверхностного контакта, и создание анаэробных условий, благоприятных для развития электрогенных микроорганизмов.

В ходе разработки конфигурации РМТЭ и выбора расположения и материала электродных систем, субстрата для растений, за основу была взята система выращивания растений на тонкослойном и малообъемном аналоге почв - панопоника, разработанная в ФГБНУ АФИ [32-34]. Ячейка РМТЭ сконструирована следующим образом. На дно емкости объемом $0.0023 \mathrm{~m}^{3}$ помещен анод, выполненный из графитового войлока площадью $300 \times 100 \mathrm{~mm}$ и толщиной $5 \mathrm{~mm}$, - позиция 3 на рис. 1. Сверху анода установлена платформа, на которой размещается растительная культура. Поверхность платформы покрыта влагопроводящей тканью, частично погруженной в питательный раствор и поднимающей его до корневой шейки растения за счет капиллярного

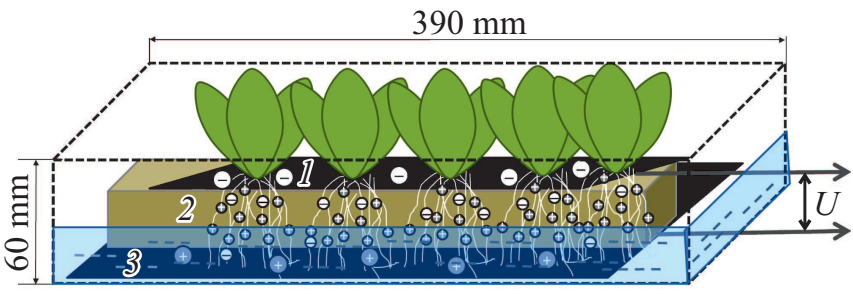

Рис. 1. Организация ячейки РМТЭ при культивировании растений методом панопоники: 1 - катод, 2 - платформа для растений, 3 - анод, и схематичное представление о процессах создания разности потенциалов за счет разделения зарядов в ризосфере, связанного с поглощением ионов корнями и их транспортом по корневой системе растений и электроактивностью микроорганизмов.

эффекта, - позиция 2 на рис. 1 . На платформе установлен катод, также изготовленный из графитового войлока площадью $300 \times 25 \mathrm{~mm}$ и толщиной $5 \mathrm{~mm}-$ позиция 1 на рис. 1. Катод покрыт тонкослойным аналогом почвы [35], на который высаживаются проросшие семена по 15 штук в ячейке. Уровень питательного раствора поддерживается постоянным - $25 \mathrm{~mm}$ от дна ячейки до половины платформы. Воздушное пространство от уровня питательного раствора до корневой шейки для аэрации корней остается равным $25 \mathrm{~mm}$. Корневая система растений и жизнедеятельность микробного сообщества, развивающегося в питательном растворе за счет использования ризодепозитов, обеспечивают возникновение электродвижущей силы между анодом и катодом, находящимися в двух средах с разными окислительно-восстановительными потенциалами и соединенных внешней цепью. Предположительно формирование градиента электрических потенциалов в такой модели РМТЭ является следствием транспорта ионов корневой системы и активностью переноса электронов микроорганизмами на анод. Предпочтительное поглощение положительно заряженных молекул $\left(\mathrm{Na}^{+}, \mathrm{K}^{+}, \mathrm{Ca}^{2+}\right)$ приводит к накоплению отрицательного заряда на катоде и недостатку электронов на аноде.

Было собрано 8 ячеек РМТЭ, которые были разделены на 4 варианта: 1) $U_{\text {control }}$ - контрольный, в который растения не высаживались; 2) $U$ - одиночная ячейка; 3) $U_{\text {parallel }}$ - три ячейки, соединенные параллельно для суммирования тока; 4) $U_{\text {series }}$ - три ячейки, соединенные последовательно для суммирования напряжения. Все ячейки были электрически изолированы друг от друга. Для съема генерируемых биотоков применялся разработанный нами неинвазивный метод автоматической регистрации биоэлектрических потенциалов (БЭП) [31], пригодный также для отслеживания функционального состояния растительных организмов и записи электрофитограмм. Для всех исследуемых вариантов автоматически каждые $15 \mathrm{~min}$ в течение всего периода вегетации растений салата регистрировались значения разности потенциалов между электродами, для чего 
между электродами была подключена плата Arduino, построенная на микроконтроллере ATmega2560 с входным сопротивлением $10^{5} \Omega$ и разрешением $10 \mathrm{bits}$.

Кроме того, периодически с помощью мультиметра M890G с входным сопротивлением $10^{7} \Omega$ проводились измерения суммарного внутреннего сопротивления между электродами $R$, включающего внутренние сопротивления корней $R_{i n t}$, сопротивления утечки, т. е. контакта между питательным раствором и электродами $R_{\text {leak }}$. Это позволяло рассчитать внутренние токи утечки по формуле:

$$
I=U / R,
$$

где $U$ - величина БЭП. Формула корректна в предположении о справедливости закона Ома для данной системы и о независимости внутренних параметров цепи от величины подаваемого напряжения. Отметим, что при измерении сопротивления с помощью мультиметра M890G на его электродах может быть напряжение, доходящее до $9 \mathrm{~V}$ в зависимости от выбранного предела измерения. Приложение такого напряжения может сказываться на электрогенных свойствах растения и влиять на результат измерения его физиологических параметров.

Важнейшей характеристикой любого топливного элемента является нагрузочная способность, т.е. способность работать длительно, с нагрузкой той или иной величины. Для определения нагрузочной способности ячейки РМТЭ измерения БЭП проводились с помощью вольтметра с входным сопротивлением $10^{7} \Omega$; параллельно ему подключались нагрузочные сопротивления $R_{\text {load }}$ в интервале от $10^{6}$ до $10 \Omega$. Удельные мощности $P$, которые могут быть получены в нагрузке при различных величинах $R_{\text {load }}$ с гипотетической площади роста растений в $1 \mathrm{~m}^{2}$, рассчитывались по формуле

$$
P=U^{2} /\left(S \cdot R_{\text {load }}\right),
$$

где $S$ - площадь исследованной ячейки в $\mathrm{m}^{2}$.

Эксперимент по исследованию электрических свойств разработанных ячеек РМТЭ был выполнен 3 раза, каждый длился 31 день до наступления технической спелости листовой зеленой массы; измерения БЭП проводили в течение 22 дней со дня посадки проросших семян в ячейки. По окончании вегетационного периода и проведения эксперимента определяли ряд основных показателей роста растений - массу надземной части и корней.

Статистическая обработка данных осуществлялась с использованием программы Excel 2010. Определялись средние значения изучаемых показателей, доверительные интервалы. Достоверность различий между вариантами оценивалась при помощи методов параметрической статистики ( $t$-критерий Стьюдента). Различия между вариантами считались достоверными при $p \leq 0.05$.

\section{2. Эквивалентная схема}

Упрощенная эквивалентная схема параллельного (рис. 2, $a$ ) и последовательного (рис. 2,b) соединения цепи из нескольких РМТЭ с многочисленными контактами корней с электродами включает в себя для каждой ячейки $(1,2,3)$ : совокупность сопротивлений корней растений $\left(R_{i n t 1}, R_{i n t 2}, R_{i n t 3}\right)$ различной величины, связанной с непрерывным развитием корневой системы и образованием новых контактов; сопротивления утечек $\left(R_{\text {leak } 1}, R_{\text {leak } 2}, R_{\text {leak } 3}\right)$, которые определяются процессами на границе между тканями растения, корнеобитаемой средой и соприкасающимися с ними электродами; совокупность ЭДС $\left(E_{1}, E_{2}, E_{3}\right)$, создаваемых как участками корней, так и за счет окислительно-восстановительных реакций в корнеобитаемой среде. Для обеспечения регистрации максимальных генерируемых значений биоэлектрических потенциалов, то есть с целью, чтобы отбираемый для измерений ток был минимален и не вызывал поляризации ткани, мы стремились к тому, чтобы сопротивление регистрирующего прибора $R_{\text {load }}$ было существенно большим, чем величины $R_{\text {int }}$ и $R_{\text {leak }}$.

\section{3. Контроль и одиночная ячейка}

В ходе регистрации биоэлектрических потенциалов в разработанных и изготовленных ячейках РМТЭ по-

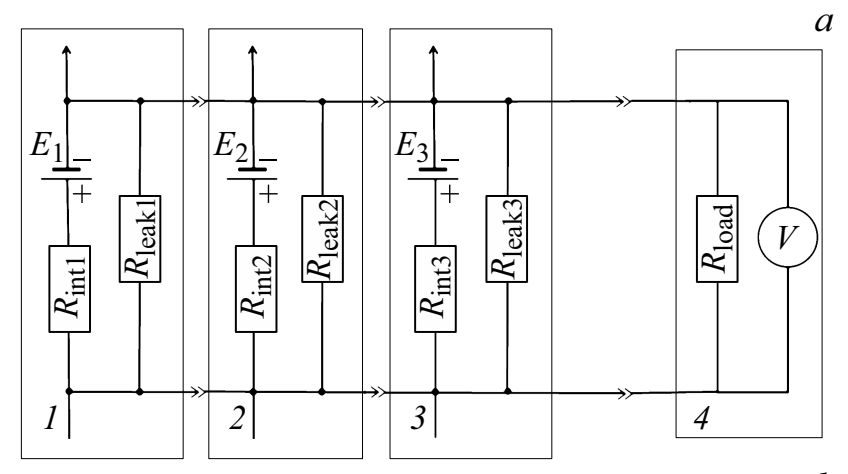

$b$

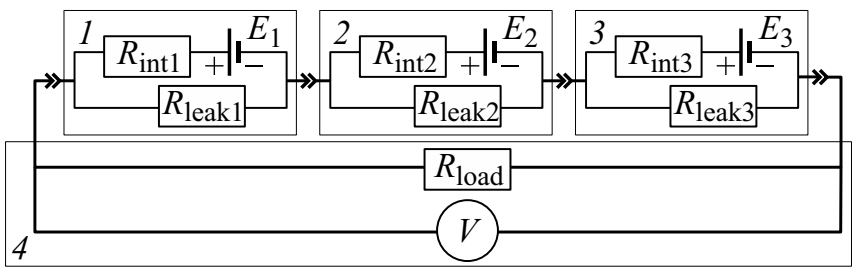

Рис. 2. Эквивалентная схема измерений биоэлектрических потенциалов: $a-$ параллельное и $b-$ последовательное соединения трех растительно-микробных топливных элементов. 1 первая ячейка, 2 - вторая ячейка, 3 - третья ячейка, $4-$ измерительный прибор; $E_{1}, E_{2}, E_{3}$ - эквивалентные ЭДС участка корнеобитаемой среды и корней для трех ячеек; $R_{i n t 1}, R_{i n t 2}$, $R_{\text {int } 3}$ - совокупность сопротивления корней для ячеек $1-3$; $R_{\text {leak } 1}, R_{\text {leak } 2}, R_{\text {leak } 3}-$ сопротивления утечек между корнями и питательной средой для ячеек $1-3 ; R_{\text {load }}-$ измерительное сопротивление регистрирующего прибора; $V$ - вольтметр. 
лучены следующие результаты. В контрольном варианте без растений была зарегистрирована некоторая разность потенциалов между установленными электродами - среднее ее значение составляло $U_{\text {control }} \sim 75 \mathrm{mV}$ в течение 17 дней проведения эксперимента, после чего величина напряжения снизилась до уровня шумов (3).

При посадке проросших семян в рассматриваемую систему наблюдается увеличение $U$ от значений, соответствующих контрольному варианту, до выхода на плато; среднее значение потенциала за период от 2-го до 21-го дня составило $\sim 170 \mathrm{mV}$ (4). Максимально зафиксированное значение $U$ составляет $250 \mathrm{mV}$ на $16-17-и ̆$ день развития, что соответствуют периоду, когда наблюдалось снижение величины разности потенциалов в контрольном варианте.

Что касается воспроизводимости, средняя величина биоэлектрического потенциала в такой конфигурации растительно-микробного топливного элемента, полученная на основе трех экспериментов, составляет $100 \pm 50 \mathrm{mV}$. Однако отклонение от этого значения и форма многосуточной кривой зависят, видимо, от вегетационного периода и продукционного потенциала семян. В частности, например, выход на плато может происходить с некоторым временным сдвигом (рис. 5).

Измеренные нагрузочные характеристики одиночной ячейки РМТЭ представлены на рис. 6. В экспериментах снижение величины $R_{\text {load }}$ от $10^{7}$ до $10^{5} \mid, \Omega$ никак не сказывалось на величине измеряемых биопотенциалов. С уменьшением $R_{\text {load }}$, т.е. с ростом нагрузки, БЭП между электродами снижается (кривая 1 на рис. 6): при $R_{\text {load }}<10 \mathrm{k} \Omega$ биопотенциал значительно падает, а

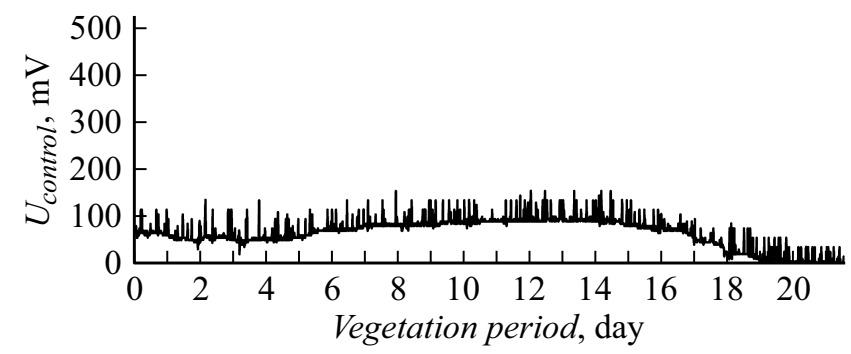

Рис. 3. Разность потенциалов в контрольном варианте ячейки РМТЭ без растения.

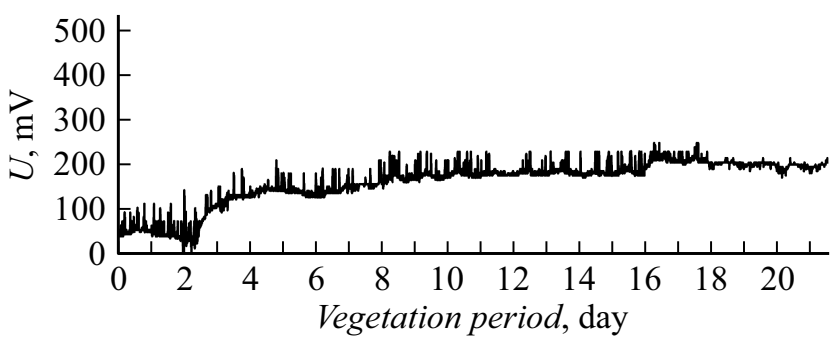

Pис. 4. Биоэлектрический потенциал в ячейке РМТЭ.

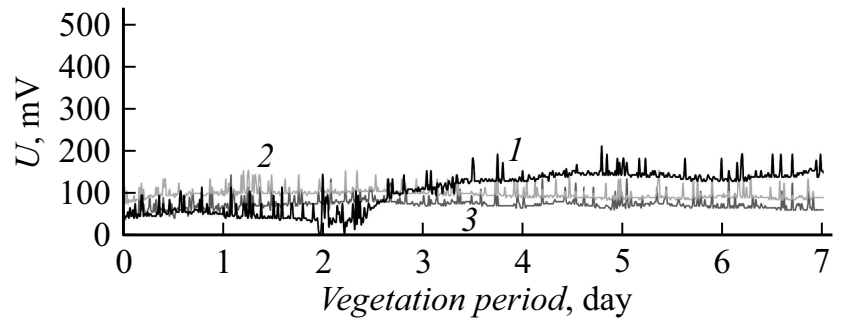

Рис. 5. Динамика биоэлектрических потенциалов в трех ячейках РМТЭ одинаковой конфигурации, измеренная при проведении экспериментов в различные периоды года: осенью (кривая 1) и летом (кривые 2,3).

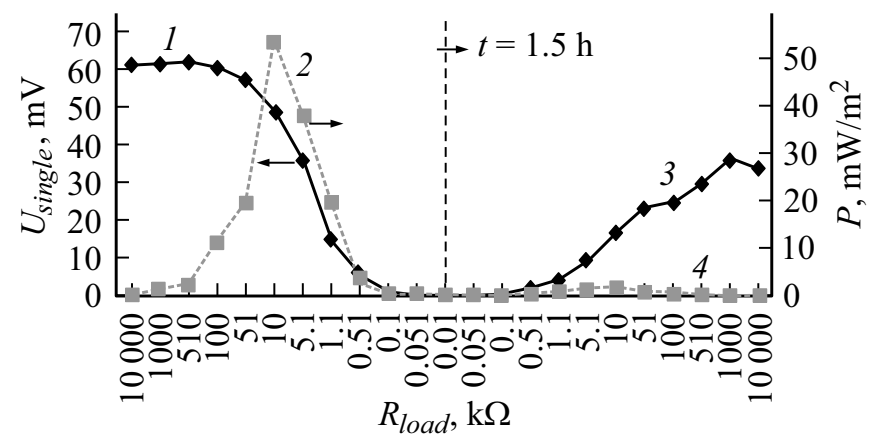

Рис. 6. Величины БЭП (кривые 1 и 3, снятые с интервалом $1.5 \mathrm{~h}$ ) и удельные мощности (кривые 2 и 4 , снятые с интервалом $1.5 \mathrm{~h}$ ) для одиночной ячейки РМТЭ в зависимости от сопротивления подключаемой нагрузки. На кривых 1 и 2 величина нагрузочного сопротивления уменьшалась, а на кривых 3 и 4 - увеличивалась от точки к точке.

при $R_{\text {load }}<500 \Omega$ уменьшается практически до нуля. После подключения малой величины $R_{\text {load }}<1 \mathrm{k} \Omega$, БЭП не только резко уменьшается, но и медленно восстанавливается до начальных значений, соответствующих нормальному физиологическому состоянию растений. Так, спустя $1.5 \mathrm{~h}$ после приложения значительной нагрузки величина БЭП регенерируется лишь наполовину (кривая 3 на рис. 6).

Величина снимаемой мощности, рассчитанной по формуле (2), растет обратно пропорционально подключенному нагрузочному сопротивлению вплоть до $R_{\text {load }} \sim 10^{5} \Omega$; при больших нагрузках мощность все еще растет, но медленнее. Ее максимальное значение достигается при величине нагрузки в $10 \mathrm{k} \Omega$ и составляет $54 \mathrm{~mW} / \mathrm{m}^{2}$ (кривая 2 на рис. 6). Эта величина падает до $1.9 \mathrm{~mW} / \mathrm{m}^{2}$ после подключения в нагрузку малых сопротивлений (кривая 4 на рис. 6).

Для поиска путей повышения электрических параметров РМТЭ были проведены эксперименты по выбору наилучшего варианта электрического соединения отдельных ячеек. Рассмотрено два варианта: параллельное соединение трех ячеек (рис. 2,a) и последовательное соединение трех ячеек (рис. $2, b)$. 


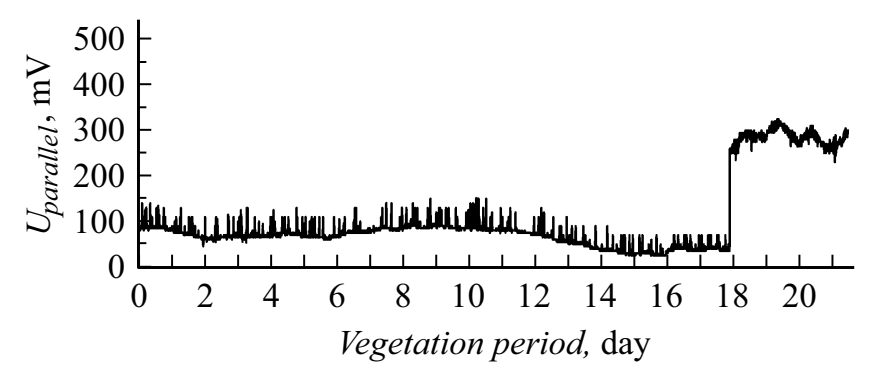

Pис. 7. Биоэлектрический потенциал в трех параллельно соединенных ячейках РМТЭ.

\section{4. Параллельное подключение}

При параллельном электрическом соединении нескольких одинаковых электрохимических ячеек, характеризуемых величиной ЭДС и внутренним сопротивлением, выходное напряжение в режиме холостого хода соответствует ЭДС одиночной ячейки. Ток в режиме „короткого замыкания“ пропорционален количеству ячеек. При величине нагрузки, сравнимой с внутренним сопротивлением ячейки, напряжение на выходе близко к величине ЭДС и незначительно растет при увеличении числа подключенных ячеек.

A priori нельзя ожидать аналогичного поведения от РМТЭ. На самом деле в рассматриваемой системе токи, генерируемые каждой из ячеек, протекают как через измерительное сопротивление, так и через внутренние сопротивления и сопротивления утечки всех остальных ячеек. Получаемые напряжения оказываются приложенными к корневым системам всех растений во всех трех ячейках в направлении, противоположном их собственной ЭДС. Поэтому возможно негативное влияние на жизнедеятельность растений и запуск механизмов для компенсации избыточного электрогенного воздействия.

В ходе экспериментального измерения получено, что на ранних этапах вегетации ( 3 дней) БЭП трех ячеек действительно соответствует значению $(\sim 100 \mathrm{mV})$, характерному и для одиночной, и для контрольной ячеек, что, видимо, связано со свойствами питательного раствора (см. ниже разд. 7). При этом повышение биоэлектрического потенциала на 2-й день развития, как это наблюдалось для одиночной ячейки, не имеет места. Наоборот, на 3-4-й день происходит небольшое снижение напряжения до средней величины $U_{\text {parallel }} \sim 70 \mathrm{mV}$ (рис. 7), что существенно расходится с данными, полученными для одиночной ячейки. Возможно, эта разница почти в $100 \mathrm{mV}$ является следствием работы компенсационного механизма, возникающего из-за влияния посторонних электрических воздействий, вызванных созданием цепи, на корневую систему растений. Интересным эффектом, который пока сложно объяснить, является существенная немонотонность временной зависимости БЭП - на 15-18-й день развития его величина существенно снижается (более, чем в 2 раза), стабилизируется на новом значении, а затем резко, скачком выходит на значения $U_{\text {parallel }}=322 \mathrm{mV}$. Это происходит на 18-й день развития, как раз когда для одиночной ячейки значение БЭП достигает максимума, а в контрольной, наоборот, падает почти до нуля.

\section{5. Последовательное подключение}

При последовательном подключении нескольких одинаковых электрохимических ячеек, характеризуемых величиной ЭДС и внутренним сопротивлением, выходное напряжение в режиме холостого хода соответствует сумме ЭДС всех ячеек. Ток в режиме „короткого замыкания“ не зависит от количества ячеек и равен таковому для одиночной ячейки. При величине нагрузки, сравнимой с внутренним сопротивлением ячейки, напряжение на выходе также пропорционально числу подключенных ячеек. При этом токи, генерируемые каждой из ячеек, обязательно протекают через все ячейки собранной батареи, и описанные выше характеристики имеют место лишь тогда, когда поляризующее действие указанных токов не влияет ни на ЭДС, ни на внутреннее сопротивление ячеек.

На начальных этапах эксперимента действительно наблюдались высокие уровни БЭП, достигающие максимальных величин $U_{\text {series }}=366 \mathrm{mV}$. Эта величина составляет примерно 70\% от утроенной величины БЭП

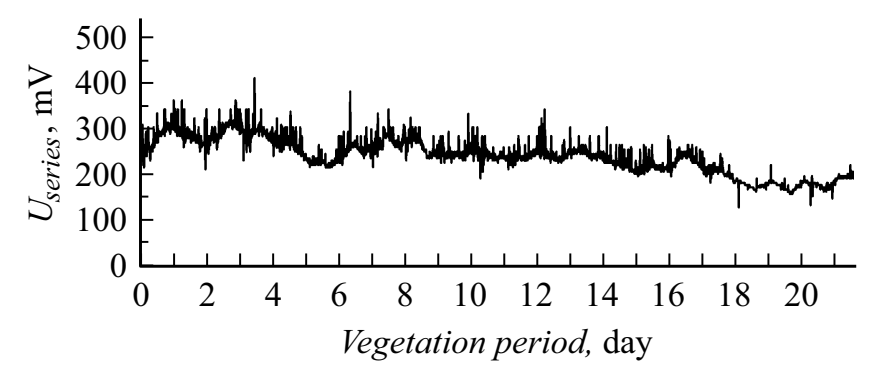

Рис. 8. Биоэлектрический потенциал в трех последовательно соединенных ячейках РМТЭ.

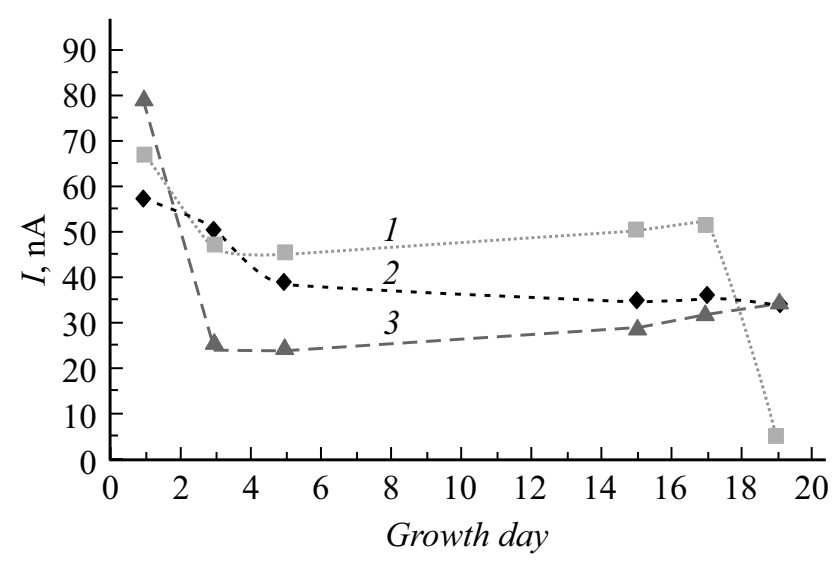

Рис. 9. Значения тока утечки РМТЭ для 1 - трех параллельно соединенных ячеек, 2 - одиночной ячейки, 3 - трех последовательно соединенных ячеек. 
Показатели роста растений в исследуемых ячейках РМТЭ

\begin{tabular}{c|c|c|c|c}
\hline \multirow{2}{*}{} & \multicolumn{2}{|c|}{ Общая масса, $\mathrm{g}$} & \multirow{2}{*}{ Урожай, $\mathrm{g} / \mathrm{m}^{2}$} \\
\cline { 3 - 4 } & \multicolumn{2}{c|}{ корней $m_{r}$} & надземной части $m_{l}$ & \\
\hline \multicolumn{2}{c|}{ Одиночная ячейка РМТЭ } & $17 \pm 1$ & $200 \pm 25$ & $5130 \pm 640$ \\
\hline \multirow{2}{*}{ Параллельное } & Ячейка 1 & $15 \pm 2$ & $190 \pm 22$ & $4870 \pm 560$ \\
соединение & Ячейка 2 & $10 \pm 2$ & $135 \pm 27$ & $3460 \pm 690$ \\
Ячейка 3 & $18 \pm 1$ & $250 \pm 29$ & $6410 \pm 740$ \\
\hline \multirow{2}{*}{ Последовательное } & Ячейка 1 & $20 \pm 2$ & $210 \pm 25$ & $5390 \pm 640$ \\
соединение & Ячейка 2 & $13 \pm 2$ & $190 \pm 26$ & $4870 \pm 670$ \\
& Ячейка 3 & $18 \pm 2$ & $234 \pm 23$ & $6000 \pm 590$
\end{tabular}

одиночной ячейки. По мере роста растений величина БЭП падает, и на 18-19-й день становится близкой к БЭП одиночной ячейки, как это видно из рис. 8. Среднее значение биопотенциала составляет $250 \mathrm{mV}$, разброс достигает $20-25 \%$.

Для измерения внутренней утечки проводились специальные измерения (см. выше). Величины тока внутренней утечки, рассчитанного по формуле (1), представлены на рис. 9. Максимально полученное значение тока в рассмотренных РМТЭ составило $81 \mathrm{nA}$. Для трех параллельно соединенных ячеек действительно наблюдается некоторое увеличение значений тока утечки, однако всего в $\sim 1.5$ раз вместо ожидаемого 3-кратного повышения.

\section{6. Показатели роста растений салата}

Масса надземной части и корней растений салата, а также его урожай с единицы площади для всех исследованных ячеек РМТЭ приведены в таблице, представленные результаты получены на основе трех экспериментов. В среднем полученные значения соответствуют таковым для растений, выращиваемых в тех же условиях, но без отбора электрического тока: получаемая масса растительной продукции обычно составляет $\sim 5-6 \mathrm{~kg} \mathrm{c} 1 \mathrm{~m}^{2}$ зоны роста [30]. Интересно отметить отклонение показателей для ячеек, расположенных посередине (ячейка 2) электрической цепи от названных выше значений.

\section{7. Обсуждение результатов}

В контрольном эксперименте, т.е. в ячейке без растений, наблюдается БЭП 70-80 mV, который падает до уровня шумов $(<20 \mathrm{mV})$ на $17-18$-й день измерений (см. выше). Известно, что в почвах без растений наблюдается проявление электрических полей, которое связывается с диффузионным ЭДС, ЭДС суспензионного эффекта, граничными потенциалами Доннана, мембранными ЭДС и диффузионно-адсорбционными потенциалами в водонасыщенных средах [36]. Видимо, в нашем случае питательная среда без растений, которая выступает как почвозаменитель и содержит аналогичные минеральные элементы в виде катионов и анионов, является своего рода гальваническим элементом с ограниченным количеством запасенной энергии.

При внедрении в среду растительного организма мы обеспечиваем систему постоянной генерацией веществ для электрохимической реакции путем преобразования световой энергии в химическую посредством растений с последующим выделением корнями органических веществ, ризодепозитов, которые, в свою очередь, в результате хемоорганогетеротрофного метаболизма микроорганизмов, развивающихся в анодном материале, способствуют протеканию электрохимический реакций. Регистрируемые значения разности потенциалов в контрольном варианте без растений, по-видимому, соответствуют наличию электрического градиента в системе, связанного с протеканием некоторых окислительновосстановительных реакций в питательном растворе, которые со временем замедляются в связи с отсутствием диффузионных ЭДС, в качестве которых и выступает корневая система растений. Известно, что ионы минеральных солей могут поступать в клетки корневой системы растений из почвы, обладающей в основном свойствами катионообменника, в результате контактного обмена с почвенными частицами - ионов $\mathrm{H}^{+}$на катионы и анионов $\mathrm{HCO}^{3-}, \mathrm{OH}^{-}$и кислот на минеральные анионы [37]. Видимо, сходные процессы характерны и при культивировании растений методом тонкослойной панопоники. Исходя из этого, ключевую роль в создание разности потенциалов вдоль корневой системы может играть процесс обменной адсорбции в системе корнеобитаемая среда-растение. Кроме того, дополнительный вклад в создание БЭП вносит развитие микроорганизмов в пористом материале анода, создавая анаэробные зоны и генерируя дополнительную ЭДС за счет окисления органических веществ, выделяемых растениями салата.

При сборке РМТЭ в последовательную и параллельную батареи, величины БЭП ведут себя совсем не так, как этого можно было бы ожидать, выступай они идеальными „гальваническими элементами“. Видимо, это связано с тем, что токи, генерируемые одним растением, 
активно влияют на электрогенез растений как в своей ячейке, так и в других ячейках электрической цепи.

Так, при параллельном соединении РМТЭ имеет место постепенное уменьшение величины БЭП с течением времени. Видимо, создаваемые в ризосферной зоне градиенты электрических потенциалов, в свою очередь, оказывают влияние на перемещение веществ, регуляции процессов жизнедеятельности клеток и растения и микроорганизмов в целом. Резкое увеличение БЭП, наблюдаемое на 18-й день развития, как раз тогда, когда для одиночной ячейки электрогенная работа корневой системы проявляется наиболее ярко, пока не находит своего объяснения.

При последовательном соединении токи, генерируемые растениями и микроорганизмами, суммируются и протекают через каждый отдельный растительный организм и микробиоту анодных частей. Видимо, это негативно влияет на способность растения к электрогенезу, приводя к снижению величины БЭП. Микроорганизмы при этом способны переключиться с генерации тока на его потребление - использовать проходящий ток для электротрофных процессов редукции углекислого газа, нитрата [38].

Судя по показателям роста растений салата, особенности электрического соединения нескольких одинаковых электрохимических ячеек не оказывали на их средние значения значимого влияния по сравнению с таковыми в варианте с одиночной ячейкой РМТЭ. Хотя в самой электрической цепи и наблюдаются некоторые отклонения значений получаемой биомассы, особенно заметные для ячейки, расположенной посередине, но в целом реализация продукционного потенциала растений салата соответствует таковой при культивировании растений без отбора электрического тока, что является положительным фактом и свидетельствует о перспективности продолжения дальнейших исследований, направленных на повышение эффективности РМТЭ.

\section{Заключение}

Таким образом, организация электрической цепи из нескольких РМТЭ является многофакторной задачей. Использование в качестве электродвижущей силы корневой системы, в частности, сельскохозяйственных растений при их культивировании методом панопоники, накладывает ряд ограничений на съем мощности с РМТЭ. В первую очередь, это наличие некоторого лимита сколько энергетических ресурсов система может отдать без ущерба для жизнедеятельности растительного организма. Это проявляется как наличие максимума мощности, отдаваемой в нагрузку, как функция величины этой нагрузки. При ее увеличении система выходит за пределы своих функциональных возможностей и требует длительного времени для восстановления электрических характеристик.
Во-вторых, при соединении нескольких РМТЭ в батарею как последовательно, так и параллельно, чистого суммирования ни тока, ни напряжения не происходит. Видимо, это связано с негативным влиянием протекающих токов или приложенных напряжений на электрогенные свойства отдельного растения и микроорганизмов в биоценозе ячейки. На наш взгляд, возможное решение данной задачи заключается в создании более сложных электрических схем, учитывающих свойства растений: адаптационный потенциал, стадию развития, состав и количество ризодепозитов идр.

\section{Конфликт интересов}

Авторы заявляют, что у них нет конфликта интересов.

\section{Список литературы}

[1] D.P.B.T.B. Strik, H.V.M. Hamelers, J.F. Snel, C.J. Buisman. International Journal of Energy Research, 32 (9), 870 (2008). DOI: $10.1002 /$ er.1397

[2] P. Chiranjeevi, D.K. Yeruva, A.K. Kumar, S.V. Mohan, S. Varjani. Microbial Electrochemical Technology. Chapter 3.8. (Elsevier, 2019). DOI: 10.1016/B978-0-444-64052-9.00022-4

[3] K. Rabaey, W. Verstraete. Trends in Biotechnology, 23 (6), 291 (2005). DOI: 10.1016/j.tibtech.2005.04.008

[4] B. Kokabian, V.G. Gude. Environmental Science: Processes \& Impacts, 15 (12), 2178 (2013). DOI: 10.1039/C3EM00415E

[5] F.T. Kabutey, Q. Zhao, L. Wei, J. Ding, P. Antwi, F.K. Quashie, W. Wang. Renewable and Sustainable Energy Reviews, 110, 402 (2019). DOI: 10.1016/j.rser.2019.05.016

[6] B.E. Logan. Microbial fuel cells (John Wiley \& Sons, 2008).

[7] D.P.B.T.B. Strik, R.A. Timmers, M. Helder, K.J. Steinbusch, H.V. Hamelers, C.J. Buisman. Trends in Biotechnology, 29 (1), 41 (2011). DOI: 10.1016/j.tibtech.2010.10.001

[8] M. Helder, W.S. Chen, E.J.M. Van der Harst, D.P.B.T.B. Strik, H.V.M. Hamelers, C.J.N. Buisman, J. Potting. Biofuels, Bioprod. Bioref., 7, 52 (2013). DOI: 10.1002/bbb.1373

[9] S.V. Mohan, G. Mohanakrishna, P. Chiranjeevi. Bioresour. Technol., 102, 7036 (2011). DOI: $10.1016 /$ j.biortech.2011.04.033

[10] Y. Feng, D. Li, J. Liu, W. He. Microbial Electrochemical Technology. Chapter 1.3. (Elsevier, 2019) DOI: 10.1016/B978-0-444-64052-9.00003-0

[11] L.D. Schamphelaire, L.V.D. Bossche, H.S. Dang, M. Höfte, N. Boon, K. Rabaey, W. Verstraete. Environ. Sci. Technol., 42 (8), 3053 (2008). DOI: 10.1021/es071938w

[12] H. Deng, Z. Chen, F. Zhao. ChemSusChem, 5 (6), 1006 (2012). DOI: $10.1002 /$ cssc.201100257

[13] В.В. Шеремет, Н.Н. Волченко, А.А. Самков. Биотехнология и общество в XXI веке, 429 (2015).

[14] P. Chiranjeevi, R. Chandra, S.V. Mohan. Ecological engineering, 51, 181 (2013). DOI: 10.1016/j.ecoleng.2012.12.014

[15] R. Piyare, A.L. Murphy, P. Tosato, D. Brunelli. In IEEE Proceedings of 2017 IEEE 42nd conference on local computer networks workshops (Singapore, IEEE Press, 2017), p. 18. 
[16] L. Doherty, Y. Zhao, X. Zhao, Y. Hu, X. Hao, L. Xu. Water Res., 85, 38 (2015). DOI: 10.1016/j.watres.2015.08.016

[17] N. Kaku, N. Yonezawa, Y. Kodama, K. Watanabe. Appl. Microbiol. Biotechnol., 79 (1), 43 (2008). DOI: $10.1007 / \mathrm{s} 00253-008-1410-9$

[18] A.P. Khare, H. Bundela. Int. J. Eng. Trend. Technol., 4(9), 4206 (2013).

[19] S. Liu, H. Song, X. Li, F. Yang. Int. J. Photoenergy, 1 (2013). DOI: $10.1155 / 2013 / 172010$

[20] M.A. Moqsud, J. Yoshitake, Q.S. Bushra, M. Hyodo, K. Omine, D.P.B.T.B. Strik. Waste Management, 36, 63 (2015). DOI: 10.1016/j.wasman.2014.11.004

[21] L. Lu, D. Xing, Z.J. Ren. Bioresource Technol., 195, 115 (2015). DOI: 10.1016/j.biortech.2015.05.098

[22] R. Nitisoravut, R. Regmi. Renewable Sustainable Energy Rev., 76, 81 (2017). DOI: 10.1016/j.rser.2017.03.064

[23] L. Gouveia, C. Neves, D. Sebastião, B.P. Nobre, C.T. Matos. Bioresource Technol., 154, 171 (2014). DOI: 10.1016/j.biortech.2013.12.049

[24] K. Wetser, E. Sudirjo, C.J. Buisman, D.P.B.T.B. Strik. Appl. Energy, 137, 151 (2015).

DOI: $10.1016 /$ j.apenergy.2014.10.006

[25] U. Schröder. Phys. Chem. Chem. Phys., 9, 2619 (2007). DOI: $10.1039 / \mathrm{B} 703627 \mathrm{M}$

[26] K.J. Parkinson. Bioelectric potentials in plants, diss (Durham University, 1963)

[27] R. Regmi. Examining different classes of plants under various operating conditions for bioelectricity production. Plant microbial fuel cell, diss (Thailand: Thammasat University, 2017)

[28] J.G. Lee, B.Y. Lee, H.J. Lee. Sci. Hortic., 110, 119 (2006). DOI: 10.1016/j.scienta.2006.06.013

[29] G. Neumann, S. Bott, M.A. Ohler, H.P. Mock, R. Lippmann, R. Grosch, K. Smalla. Front Microbiol., 5, 2 (2014). DOI: $10.3389 /$ fmicb.2014.00002

[30] Т.Э. Кулешова, И.Н. Черноусов, О.Р. Удалова, Л.М. Аникина, Ю.В. Хомяков, А.В. Александров, И.С. Середин, С.В. Феофанов, С.А. Щеглов, Н.Р. Галль, Г.Г. Панова. Биофизика, 65 (1), 112 (2020). DOI: $10.31857 /$ S0006302920010147

[T.E. Kuleshova, I.N. Chernousov, O.R. Udalova, L.M. Anikina, Yu.V. Khomyakov, A.V. Aleksandrov, I.S. Seredin, S.V. Feofanov, S.A. Shcheglov, N.R. Gall, G.G. Panova. Biofizika, 65 (1), 112 (2020).

DOI: $10.1134 / \mathrm{S} 0006350920010121]$

[31] Т.Э. Кулешова, А.В. Бушлякова, Н.Р. Галль. Письма в ЖТФ, 45 (5), 6 (2019).

DOI: 10.21883/PJTF.2019.05.47387.17541 [T.E. Kuleshova, A.V. Bushlyakova, N.R. Gall. Tech. Phys. Lett., 45 (3), 190 (2019). DOI: 10.1134/S1063785019030106]

[32] Е.И. Ермаков. Избранные труды (Изд-во ПИЯФ РАН, СПб, 2009)

[33] Ю.И. Желтов, Г.Г. Панова. Патент РФ на полезную модель № 108705, Бюл. № 27 (2011).

[34] Г.Г. Панова, И.Н. Черноусов, О.Р. Удалова, А.В. Александров, И.В. Карманов, Л.М. Аникина, В.Л. Судаков, В.П. Якушев. Доклады Российской академии сельскохозяйственных наук, 4, 17 (2015).

[35] И.Н. Черноусов, Г.Г. Панова, О.Р. Удалова, А.В. Александров. Патент РФ на полезную модель № 189309, Бюл. № 15 (2019).
[36] А.И. Поздняков, Л.А. Позднякова, А.Д. Позднякова. Cmaционарные электрические поля в почвах (КМК Scientific Press Ltd, M., 1996)

[37] С.С. Медведев. Физиология растений: учебник (БХВПетербург, СПб., 2012).

[38] B.E. Logan, R. Rossi, A. Ragab, P.E. Saikaly. Nature Rev. Microbiolog., 17, 307 (2019). DOI: 10.1038/s41579-0190173-X 